\title{
T Cell Motility-How Is It Regulated?
}

\author{
Karl-Gösta Sundqvist * \\ Department of Laboratory Medicine, Division of Clinical Immunology, Karolinska Institute and Clinical Immunology and \\ Transfusion Medicine Karolinska University Hospital, Stockholm, Sweden
}

Keywords: lipoprotein receptor-related protein 1, thrombospondin-1, chemokine receptors, integrins, adhesion, motility

\section{OPEN ACCESS}

Edited by:

Bernard Malissen,

INSERM U1104 Centre

d'immunologie de Marseille-Luminy

(CIML), France

Reviewed by:

Vincenzo Di Bartolo,

Institut Pasteur, France

*Correspondence:

Karl-Gösta Sundqvist

Karl.Sundqvist@sll.se;

Karl-G.Sundqvist@ki.se

Specialty section: This article was submitted to T Cell Biology,

a section of the journal

Frontiers in Immunology

Received: 29 July 2020 Accepted: 19 November 2020 Published: 11 December 2020

Citation:

Sundqvist K-G (2020) T Cell Motility-How is it Regulated?

Front. Immunol. 11:588642. doi: 10.3389/fimmu.2020.588642

\section{INTRODUCTION}

Cell motility and its regulation attract enormous interest. This is particularly evident in immunology with a literature explosion on $\mathrm{T}$ cell motility in search for antigen, surveillance of the organism for infected cells and cancer cells but also pathological infiltration of T cells in inflammatory diseases. The prevailing concept is that cell motility, including ameboid-like motility in T cells, is driven by integrin and chemokine receptor signaling and reorganization of actin (1-7). There is, however, no consensus on the mechanism of ameboid movement in general, on the precise mechanisms of cell motion, and how $\mathrm{T}$ cells adapt their motility to different environments and activities (6-13). It also remains unclear how cell polarity, the basis of directed cell movements, is directed (14), and why T cell motility and extravasation, as well as motility of amoebae, are dependent on protein synthesis (15-18).

Contemporary motility research is focusing on outside-in signaling through chemokine receptor and integrin transmembrane signaling to the cytomusculature (1-14) or on a regulatory role of cytomuscular components on plasma membrane molecules (19). However, motility of a search and surveillance cell, like the T cell, is likely to depend on cell-intrinsic regulation and to be adaptive to its environment. Here I discuss cell-intrinsic regulation of $\mathrm{T}$ cell polarity, motility and adhesion through an intra-plasma membrane crosslinking cascade, which promotes integrin and chemokine receptor effects on motility. This cascade is triggered by the transmembrane receptor low density lipoprotein receptor-related protein 1 (LRP1) and co-receptor calreticulin through their ligand thrombospondin-1 (TSP-1). This cell-intrinsic mechanism senses and adapts motility to the microenvironment and antagonizes integrin-dependent contacts through shedding of LRP1. Antigen stimulation targets LRP1 and TSP-1 suggesting that the cell-intrinsic motility mechanism has a central functional role in T cells.

LRP1 and TSP-1 are uniquely equipped for crosslinking interactions due to their size and numerous binding sites for other molecules $(20,21)$. LRP1 consists of an $\alpha$-chain $(515 \mathrm{kDa})$ containing ligand-binding domains, a $\beta$-chain $(85 \mathrm{kDa})$ containing the transmembrane domain and the cytoplasmic tail. TSP1 is a $450-\mathrm{kDa}$ adhesive glycoprotein composed of three identical disulfidelinked polypeptide chains that display binding sites for various cell surface receptors and other molecules including LRP1, calreticulin, integrins, CD47, heparan sulfate proteoglycans and fibronectin. 


\section{CELL SURFACE CROSSLINKING-A FUNDAMENTAL MOTOGENIC PRINCIPLE}

The formation of motile active cell edges requires actin nucleation and polymerization by preformed actin filaments and nucleators, including the Arp2/3 complex, WASP and formins and linkage to the plasma membrane through ezrin-moesin-radixin. Cell surface receptors depend on this association to the actomyosin system for their expression, localization and function. Actomyosin contractility has a central role for cell motility and is generated by myosin-exerted force on actin filaments.

A key question is how the actomyosin machinery in cells with ameboid-like motility and with a key role to search and surveil is regulated. In ameboid three-dimensional migration myosin is thought to start the motile process. However, there is substantial evidence that actin rearrangements and motility are directed at the level of the plasma membrane through crosslinking of cell surface receptors (22-25). Cytoplasmic spreading on insolubilized ligands depends on the crosslinking principle. The power of this mechanism is evident by its independence of the specificity of the ligands (26) although physiological crosslinking in adherent cells is mediated through integrins. Ameboid-like T cell motility in three-dimensional environments independent of adhesive contacts may therefore be postulated to require cell-intrinsic crosslinking of plasma membrane receptors.

\section{MOTILITY AND SENSING THROUGH A CROSSLINKING CASCADE}

In support of the concept that motility is directed at the plasma membrane level, early work showed that $\mathrm{T}$ cell motility is associated with surface expression of a complex of endogenous high-molecular weight proteins and a $55 \mathrm{kDa}$ protein maintained by contact with type 1 collagen matrices and other cells but lost by contact with plastic $(16,27)$. Subsequently, the endogenous high molecular weight proteins LRP1 and TSP-1 have been shown to regulate $\mathrm{T}$ cell motility and integrin-dependent adhesion through collaboration with other proteins, including the $50 \mathrm{kDa}$ protein calreticulin, CD47 and CD26 (28-34). Zinc chloride stabilizes this complex of motogenic cell surface molecules while enhancing motility (28).

LRP1 and associated calreticulin trigger a polarized motile morphology and migration through the $\mathrm{NH}$-terminal region of TSP-1 and interaction of its distal COOH-terminal region with CD47, but TSP-1 may also crosslink other cell surface receptors (Figure 1). On the contrary, TSP-1 does not trigger motility through LRP1-calreticulin indicating that the motogenic crosslinking cascade is directed and implicates a regular controlled process. This directed crosslinking may explain how $\mathrm{T}$ cell polarity is controlled. LRP1 induces motility by binding intact $170 \mathrm{kDa}$ TSP1 and a $130 \mathrm{kDa}$ TSP-1 fragment and maintains the localization of TSP-1 within the plasma membrane of T cells (30, 32). Inhibition of LRP1 hence changes the distribution of TSP-1 from discontinuous patchy on cells with different motile morphologies to a cap-like localization on spherical cells. This association of LRP1 and TSP-1 probably explains why silencing, or blocking ligand binding of LRP1, inhibit T cell motility (28-34). In contrast to endogenous TSP-1, exogenous TSP-1 or a peptide mimetic of its $\mathrm{NH}$-terminal calreticulin binding site inhibit motility (28), which strongly supports that motility is triggered by endogenous LRP1-calreticulin complexes in cis via TSP-1. It is also worthy to note that MMP-9 stimulates three-dimensional $\mathrm{T}$ cell motility in an extracellular matrix model independent of proteolysis (35), which may reflect that it is a ligand for LRP1 (36) and hence may stimulate the cell-intrinsic motogenic cascade.

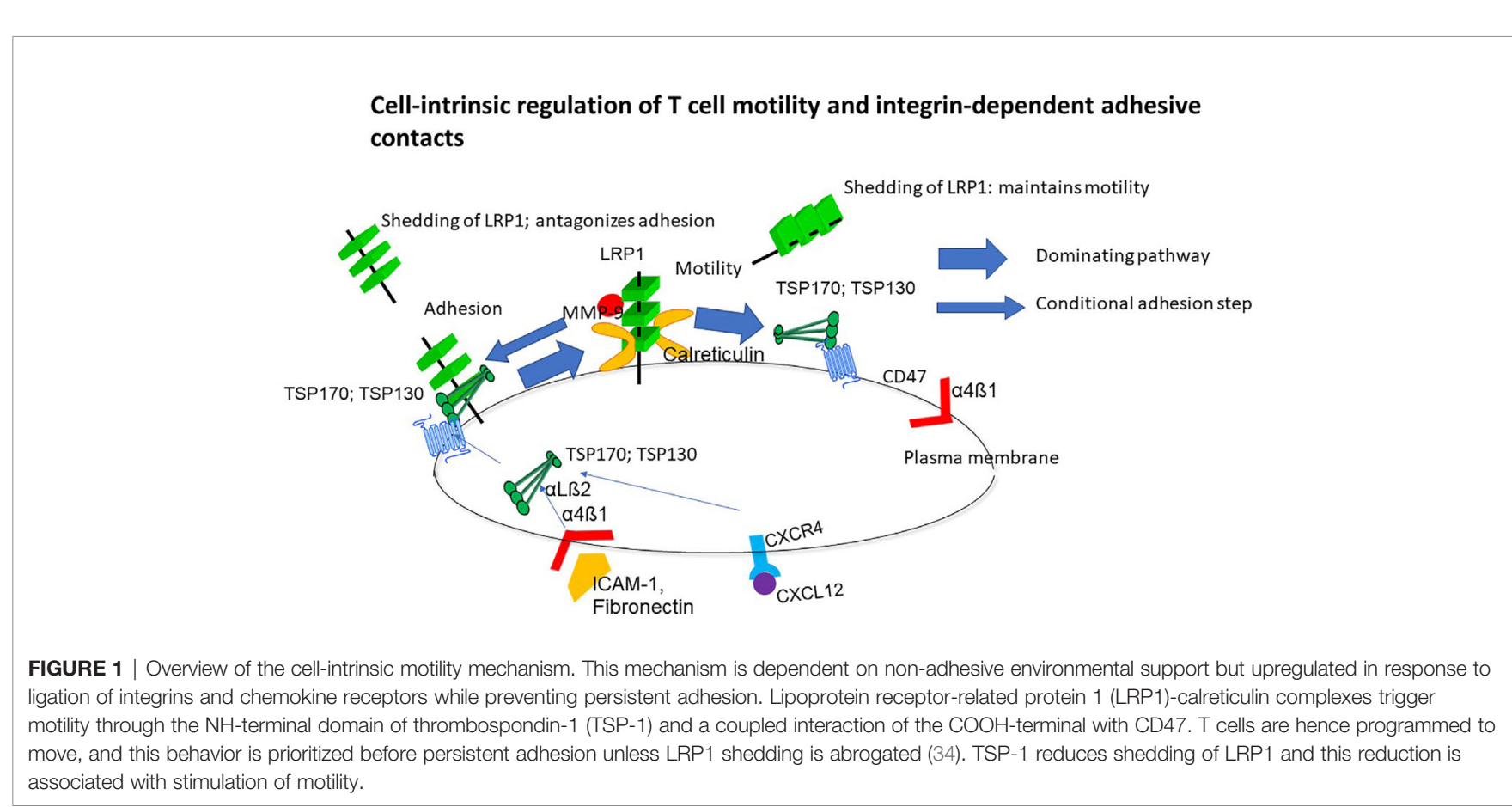


T cell motility depends on the LRP1-regulated motility mechanism (28-34) and is markedly higher in cells contacting collagen matrices and other cells than plastic $(16,27)$, which implies that this mechanism senses the cellular microenvironment. This conclusion is reinforced by the fact that the LRP1-regulated motility mechanism maintains a $\mathrm{T}$ cell phenotype for scanning of surrounding structures by preventing cytoplasmic spreading with disappearance of microvilli and arrest in cells contacting integrin ligands $(28,31,34)$. The LRP1-regulated motility mechanism further integrates sensing of the $\mathrm{T}$ cell microenvironment through integrin and chemokine receptors $(30,32)$. This may explain how cells coordinate environmental signaling through multiple, often redundant receptors.

\section{A LABILE MECHANISM FOR SENSING AND MOTILITY THROUGH DEPENDENCE OF PROTEIN SYNTHESIS ON ENVIRONMENTAL SUPPORT}

$\mathrm{T}$ cell motility and extravasation, as well as motility of ameba, depend on protein synthesis although the driving of motility by actin reorganization and signaling does not (15-18). A clue to the dependence of motility on protein synthesis is that cell surface proteins sensing the environment and regulating motility have a high turnover $(16,28,29)$. Shedding of LRP1 (34) may contribute to this but also internalization and degradation. It is reasonable to assume that contact with collagen matrices and other cells maintains motility by supporting synthesis of motogenic proteins since protein synthesis requires environmental support (37). The dependence on sensing of the environment further suggests that the LRP1-directed motility mechanism is responsible for the dependence of motility on confinement.

\section{THREE-DIMENSIONAL (3D) T CELL MIGRATION DEPENDS ON THE LRP1- AND TSP-1 DIRECTED MOTILITY MECHANISM}

It is important to define the influence on T cell motility of the LRP1directed motility mechanism and signaling through integrins and chemokine receptors. This issue is well illustrated by experiments studying T cells in a 3D environment. T cell motility into a collagen matrix hence depends on the LRP1-directed motility mechanism (28-34). In contrast, signaling through integrin and chemokine receptors does not give $\mathrm{T}$ cells ability to enter $3 \mathrm{D}$ matrices but enhances existing capacity to enter such matrices (38). However, in $\mathrm{T}$ cells with capacity to enter collagen matrices, infiltration is markedly enhanced through expression of collagen-binding integrins (39). T cells expressing collagen receptors rapidly penetrate and unlike fibroblasts and macrophages do not undergo cytoplasmic spreading on top of the collagen. This is probably important for T cell surveillance and protection against infections in non-lymphoid organs. Collagen-binding integrins are hence crucial for $\mathrm{T}$ cell infiltration in tissues affected by inflammatory diseases $(40,41)$. It should be mentioned that $\mathrm{T}$ cell motility in collagen matrices has been reported to be integrin-independent (42). However, this conclusion may reflect use of cells lacking collagenbinding integrins (ConA-stimulation for 3 days) since expression of these integrins require long-term activation and lectins have been reported to inhibit integrins (43).

\section{ADHESION CONTROL}

The LRP1-regulated motility mechanism promotes integrindependent adhesive contacts (29). However, shedding of LRP1 maintains $\mathrm{T}$ cell motility during contact with integrin ligands (34). Accordingly, abrogation of shedding by a broad-spectrum metalloprotease inhibitor (34) causes accumulation of LRP1 and TSP-1 at the cell edge, firm integrin-dependent adhesion, apolar cytoplasmic spreading, and motility arrest. In contrast, the intrinsic capacity of the LRP1-regulated motility mechanism to reduce shedding is set to merely counterbalance adhesion and prioritize motility.

The chemokines CXCL12 and CCL5, and contact with integrin ligands, stimulate transport of TSP-1 and LRP1 to the cell surface $(30,32)$. CXCL12 and integrin ligands induce surface expression of intact TSP-1 and a 130000 MW TSP-1 fragment, which associate with LRP1, while preventing expression of 110,000 MW TSP-1 fragment. This fragment does not associate with LRP1 and correlates with de-adhesion. This suggests that differential cell surface expression of TSP-1 and TSP-1 fragments regulate T cell motility and adhesive contacts in collaboration with LRP1.

\section{A MECHANISM FOR SEARCH AND SURVEILLANCE}

The LRP1-regulated motility mechanism hence combines an ability to sense environmental structures independent of conventional receptors and adapt to this sensing. Sensing and motility are hence tightly coupled indicating that this mechanism is important for T cell search and surveillance. Shedding of LRP1 may further be critical to promote search for antigen by preventing persistent adhesive contacts and may prevent this large molecule from interference with TCR-pMHC interactions. The ability to integrate and respond to integrin and chemokine receptor signals further endows this mechanism with a global sensing capacity consistent with a key role for $\mathrm{T}$ cell search and surveillance. Integrin and chemokine receptor signals stimulate this mechanism through enhanced TSP1 transport to the cell surface antagonizing shedding of LRP1 (30, 32, 34). This implies that a labile mechanism for sensing and motility is enhanced by integrin and chemokine receptor signals.

\section{LIGATION OF TCR/CD3 AND CD28 TARGETS LRP1 AND TSP-1}

TCR-induced arrest upon antigen recognition, cytoplasmic spreading and actin polymerization are considered central in 
T cell biology and thought to represent decision to enter an activation program (44). Collaboration between TCR/CD3 ligation and ligation of LFA-1 enhances transport of TSP-1 to the cell surface, which antagonizes shedding of LRP (29, 30, 34). Ligation of CD28 also inhibits shedding of LRP1 but through a distinct mechanism (35). Antigen stimulation promotes contact between $\mathrm{T}$ cells and antigen-presenting cells probably through upregulated TSP-1 and reduced LRP1 expression (34). This indicates that the cell-intrinsic regulation of motility and integrindependent adhesion is important for TCR-induced activation.

\section{THERAPEUTIC IMPLICATIONS}

The cell-intrinsic motility mechanism represents a therapeutic target for interference with $\mathrm{T}$ cell activity, for example in inflammatory diseases. It is interesting in this context that the cornerstone therapy for inflammatory diseases, methotrexate,

\section{REFERENCES}

1. Griffith JW, Sokol CL, Luster AD. Chemokines and chemokine receptors: positioning cells for host defense and immunity. Annu Rev Immunol (2014) 32:659-702. doi: 10.1146/annurev-immunol-032713-120145

2. Marelli-Berg FM, Cannella L, Dazzi F, Mirenda V. The highway code of T cell trafficking. J Pathol (2008) 214:179-89. doi: 10.1002/path.2269

3. Bromley SK, Mempel TR, Luster AD. Orchestrating the orchestrators: chemokines in control of T cell traffic. Nat Immunol (2008) 9:970-80. doi: 10.1038/ni.f.213

4. Cahalan MD, Parker I. Choreography of cell motility and interaction dynamics imaged by two-photon microscopy in lymphoid organs. Annu Rev Immunol (2008) 26:585-626. doi: 10.1146/annurev.immunol.24.021605. 090620

5. Krummel MF, Bartumeus F, Gerard G. T cell migration, serach strategiers and mechanisms. Nat Rev Immunol (2016) 16:193-201. doi: 10.1038/nri.2015.16

6. Liu YJ, Le Berre M, Lautenschlaeger F, Maiuri P, Callan-Jones A, Heuzé M, et al. Confinement and low adhesion induce fast amoeboid migration of slow mesenchymal cells. Cell (2015) 160:659-72. doi: 10.1016/j.cell.2015.01.007

7. Hons M, Kopf A, Hauschild R, Leithner A, Gaertner F, Abe J, et al. Chemokines and integrins independently tune actin flow and substrate friction during intranodal migration of T cells. Nat Immunol (2018) 19:606-16. doi: 10.1038/s41590-018-0109-Z

8. Yamada KM, Sixt M. Mechanisms of 3D cell migration. Nat Rev Mol Cell Biol (2019) 20:738-52. doi: 10.1038/s41580-019-0172-9

9. Winkler B, Aranson IS, Ziebert F. Confinement and substrate topography control cell migration in a 3D computational model. 2019. Commun Phys (2019) 2. Article number: 82. doi: 10.1038/s42005-019-0185-x

10. Jacobelli J, Friedman RS, Conti MA, Lennon-Dumenil AM, Piel M, Sorensen $\mathrm{CM}$, et al. Confinement-optimized three-dimensional $\mathrm{T}$ cell amoeboid motility is modulated via myosin IIA-regulated adhesions. Nat Immunol (2010) 10:953-61. doi: 10.1038/ni.1936

11. Katakai T, Habiro K, Kinashi T. Dendritic Cells Regulate High-Speed Interstitial $\mathrm{T}$ Cell Migration in the Lymph Node via LFA-1/ICAM-1. J Immunol (2013) 191:1188-99. doi: 10.4049/jimmunol.1300739

12. Ley K, Laudanna C, Cybulsky MII, Nourshargh S. Getting to the site of inflammation: the leukocyte adhesion cascade updated. Nat Rev Immunol (2007) 7:678-89. doi: 10.1038/nri2156

13. Shao D, Levine H, Rappel W-J. Coupling actin flow, adhesion, and morphology in a computational cell motility model. Proc Natl Acad Sci U.S.A. (2012) 10918:6851-6. doi: 10.1073/pnas.1203252109

14. Rappel WJ, Edelstein-Keshet L. Mechanisms of Cell Polarization. Curr Opin Syst Biol (2017) 3:43-53. doi: 10.1016/j.coisb.2017.03.005 stimulates this motility mechanism. This is consistent with an immunoregulatory function of this mechanism and suggests that methotrexate, at the relatively low concentrations used to treat inflammatory diseases, is immunoregulatory rather than inhibitory (45).

\section{AUTHOR CONTRIBUTIONS}

The author confirms being the sole contributor of this work and has approved it for publication.

\section{FUNDING}

This work was supported by the Swedish Cancer Foundation and the Swedish Research Council.
15. Wilkinson PC. The locomotor capacity of human lymphocytes and its enhancement by cell growth. Immunology (1986) 57:281-9.

16. Arencibia I, Pedari L, Sundqvist KG. Induction of motility and alteration of surface membrane polypeptides in lymphocytes by contact with autologous and allogeneic fibroblasts. Exp Cell Res (1987) 172:124-33. doi: 10.1016/00144827(87)90099-1

17. Wiebke JL, Quinlan WM, Graham L, Doerschuk CM. Effect of Protein Synthesis Inhibition by Cycloheximide on Lymphocyte Circulation. Lab Invest (1994) 70:392-8.

18. Clotworthy M, Traynor D. On the effects of cycloheximide on cell motility and polarisation in Dictyostelium discoideum. BMC Cell Biol (2006) 7. Article number: 5. doi: 10.1186/1471-2121-7-5

19. Gowrishankar K, Ghosh S, Saha S, Rumamol C, Mayor S, Rao M. Active Remodeling of Cortical Actin Regulates Spatiotemporal Organization of Cell Surface Molecules. Cell (2012) 149:1353-67. doi: 10.1016/j.cell.2012.05.008

20. Lillis AP, Van Duyn LB, Murphy-Ullrich JE, Strickland DK. LDL receptor-related protein 1: unique tissue-specific functions revealed by selective gene knockout studies. Physiol Rev (2008) 88:887-918. doi: 10.1152/physrev.00033.2007

21. Resovi A, Pinessi D, Chiorino G, Taraboletti G. Current understanding of the thrombospondin-1 interactome. Matrix Biol (2014) 37:83-91. doi: 10.1016/ j.matbio.2014.01.012

22. Taylor RB, Duffus WP, Raff MC, de Petris S. Redistribution and pinocytosis of lymphocyte surface immunoglobulin molecules induced by antiimmunoglobulin antibody. Nat New Biol (1971) 233:225-9. doi: 10.1038/ newbio233225a0

23. Sundqvist KG. Redistribution of surface antigens-a general property of animal cells? Nat New Biol (1972) 239:147-9. doi: 10.1038/newbio239147a0

24. Sundqvist KG, Ehrnst A. Cytoskeletal control of surface membrane mobility. Nature (1976) 264:226-31. doi: 10.1038/264226a0

25. Flanagan J, Koch GL. Cross-linked surface IG attaches to actin. Nature (1978) 273:278-81. doi: 10.1038/273278a0

26. Wanger L, Otteskog P, Sundqvist KG. Anchorage and lymphocyte function. Antibodies as adhesion and spreading factors for human $\mathrm{T}$ lymphocytes. Immunology (1984) 52:519-23.

27. Sundqvist KG, Otteskog P. A labile antigen complex at the lymphocyte surface: the effect of the substratum on its expression. J Immunol (1987) 1383:825-32.

28. Li SS, Forslöw A, Sundqvist KG. Autocrine regulation of T cell motility by calreticulin-thrombospondin-1 interaction. J Immunol (2005) 174:654-61. doi: 10.4049/jimmunol.174.2.654

29. Li SS, Liu Z, Uzunel M, Sundqvist KG. Endogenous thrombospondin-1 is a cell-surface ligand for regulation of integrin-dependent T-lymphocyte adhesion. Blood (2006) 108:3112-20. doi: 10.1182/blood-2006-04-016832 
30. Liu Z, Christensson M, Forslöw A, De Meester I, Sundqvist KGA. CD26controlled cell surface cascade for regulation of $\mathrm{T}$ cell motility and chemokine signals. J Immunol (2009) 183:3616-24. doi: 10.4049/jimmunol.0804336

31. Bergström SE, Bergdahl E, Sundqvist KG. A cytokine-controlled mechanism for integrated regulation of T-lymphocyte motility, adhesion and activation. Immunology (2013) 140:441-55. doi: 10.1111/imm.12154

32. Talme T, Bergdahl E, Sundqvist KG. Regulation of T-lymphocyte motility, adhesion and de-adhesion by a cell surface mechanism directed by low density lipoprotein receptor-related protein 1 and endogenous thrombospondin-1. Immunology (2014) 142:176-92. doi: 10.1111/imm.12229

33. Bergström SE, Uzunel M, Talme T, Bergdahl E, Sundqvist KG. Antigeninduced regulation of T-cell motility, interaction with antigen-presenting cells and activation through endogenous thrombospondin-1 and its receptors. Immunol (2015) 144:687-703. doi: 10.1111/imm.12424

34. Panezai J, Bergdahl E. Sundqvist KG. T-cell regulation through a basic suppressive mechanism targeting low-density lipoprotein receptor-related protein 1. Immunology (2017) 152:308-27. doi: 10.1111/imm.12770

35. Ivanoff A, Ivanoff J, Hultenby K, Sundqvist KG. Infiltrative capacity of $\mathrm{T}$ leukemia cell lines: A distinct functional property coupled to expression of matrix metalloproteinase-9 (MMP-9) and tissue inhibitor of metalloproteinases-1 (TIMP-1). Clin Exp Metast (1999) 17:695-711. doi: 10.1023/A:1006749304315

36. Hahn-Dantona E, Ruiz JF, Bornstein P, Strickland DK. The low density lipoprotein receptor-related protein modulates levels of matrix metalloproteinase 9 (MMP-9) by mediating its cellular catabolism. J Biol Chem (2001) 276:15498-503. doi: 10.1074/jbc.M100121200

37. Ben-Ze'ev A, Farmer SR, Penman S. Protein synthesis requires cell-surface contactwhile nuclear events respond to cell shape in anchorage-dependent fibroblasts. Cell (1980) 21:365-72. doi: 10.1016/0092-8674(80)90473-0

38. Ivanoff J, Talme T, Sundqvist KG. The role of chemokines and extracellular matrix components in the migration of T lymphocytes into three-dimensional substrata. Immunol (2005) 114:53-62. doi: 10.1111/j.1365-2567.2004.02005.x

39. Sundqvist KG, Hauzenberger D, Hultenby K, Bergström SE. T lymphocyte infiltration of two- and three-dimensional collagen substrata by an adhesive mechanism. Exp Cell Res (1993) 206:100-10. doi: 10.1006/excr.1993.1125
40. De Fougerolles AR, Sprague AG, Nickerson-Nutter CL, Chi-Rosso G, Rennert PD, Humphrey Gardner H, et al. Regulation of inflammation by collagenbinding integrins $\alpha 1 \beta 1$ and $\alpha 2 \beta 1$ in models of hypersensitivity and arthritis. J Clin Invest (2000) 105:721-9. doi: 10.1172/JCI7911

41. Martin Richter M, Ray SJ, Chapman TJ, Austin SJ, Rebhahn J, Mosmann TR, et al. Topham DJ. Collagen Distribution and Expression of Collagen-Binding $\alpha_{1} \beta_{1}$ (VLA-1) and $\alpha_{2} \beta_{1}$ (VLA-2) Integrins on CD4 and CD8 T Cells during Influenza Infection. J Immunol (2007) 178:4506-16. doi: 10.4049/ jimmunol.178.7.4506

42. Friedl P, Entschladen F, Conrad C, Niggemann B, Zänker KS. CD4 ${ }^{+} \mathrm{T}$ lymphocytes migrating in three-dimensional collagen lattices lack focal adhesions and utilize $\beta 1$ integrin-independent strategies for polarization, interaction with collagen fibers and locomotion. Eur J Immunol (1998) 28:2331-43. doi: 10.1002/(SICI) 1521-4141(199808)28:08<2331::AIDIMMU2331>3.0.CO;2-C

43. Hemler ME, Jacobson JG. Cell matrix adhesion-related proteins VLA-1 and VLA-2: regulation of expression on T cells. J Immunol (1987) 138:941-2948.

44. Fooksman DR, Vardhana S, Vasiliver-Shamis G, Liese J, Blair D, Waite J, et al. Functional Anatomy of T Cell Activation and Synapse Formation. Annu Rev Immunol (2010) 28:79-105. doi: 10.1146/annurev-immunol-030409-101308

45. Talme T, Bergdahl E, Sundqvist KG. Methotrexate and its therapeutic antagonists, caffeine and theophylline, target a motogenic T-cell mechanism driven by thrombospondin-1 (TSP-1). Eur J Immunol (2016) 46:1279-90. doi: 10.1002/eji.201546122

Conflict of Interest: The author declares that the research was conducted in the absence of any commercial or financial relationships that could be construed as a potential conflict of interest.

Copyright (c) 2020 Sundqvist. This is an open-access article distributed under the terms of the Creative Commons Attribution License (CC BY). The use, distribution or reproduction in other forums is permitted, provided the original author(s) and the copyright owner(s) are credited and that the original publication in this journal is cited, in accordance with accepted academic practice. No use, distribution or reproduction is permitted which does not comply with these terms. 